\title{
ORGANIZAÇÃO DO TRABALHO EM ENFERMAGEM: IMPLICAÇÕES NO FAZER E VIVER DOS TRABALHADORES DE NÍVEL MÉDIO
}

\author{
WORK ORGANIZATION IN NURSING: IMPLICATIONS FOR WORK \\ PERFORMANCE AND LIFE OF UNREGISTERED NURSES
}

\author{
Denise Pires 1 \\ Francine Lima Gelbcke 2 \\ Eliane Matos 3
}

Resumo Este artigo reflete acerca da organização do trabalho da enfermagem no contexto do trabalho em saúde. Sustenta-se teoricamente nas formulações do materialismo histórico-dialético sobre o processo de trabalho humano, em uma abordagem crítica do conceito de profissão elaborado pela sociologia das profissões e em algumas teorias do campo da administração que vêm influenciando o trabalho da enfermagem. Teve por base os dados obtidos em 6 (seis) pesquisas de campo que resultaram em 3 (três) dissertações de mestrado e 3 (três) teses de doutorado que trataram do tema, utilizando a abordagem da pesquisa qualitativa e envolvendo a participação de representantes dos diversos grupos que compõe a equipe de enfermagem. Conceitua organização do trabalho incluindo a perspectiva da vivência nos locais de trabalho e das relações macrossociais. Ressalta que as transformações que vêm ocorrendo no mundo do trabalho têm influenciado o trabalho em saúde, mas que o modelo de organização continua influenciado pela lógica taylorista e que é preciso pensar novas formas de organização do trabalho que possibilitem uma ação mais participativa dos trabalhadores. Conclui que a realidade da organização do trabalho da enfermagem pode ser mudada pela ação coletiva dos profissionais de enfermagem, em aliança com os demais setores organizados da sociedade e atendendo as necessidades dos usuários dos serviços.

Palavras-chave trabalho em saúde; organização do trabalho: organização do trabalho da enfermagem; trabalhadores de enfermagem de nível médio.
Abstract This article presents a reflection concerning the organization of work in nursing in the context of the organization of work in health care. It is theoretically sustained by the historical-dialectic materialism upon human labor process and it is also based upon a critical vision about the profession concept elaborated by the sociology of professions and upon some theories in the field of administration that have been influenced nursing work. The study is based upon data obtained in six (6) field research, three (3) of which resulted in master's theses and three (3) of which resulted in doctorate dissertations. These six researches dealt with the theme of the organization of work in health and nursing, using a qualitative approach and involving the participation of diverse members of nursing team. This study conceptualizes the organization of work from both the workplace perspective and macro-social relationships. It highlights that the transformations that have occurred in the world of work have influenced the work in health care, but the organizational model of work continues influenced by the Taylor's logic of work organization, suggesting that we should think of new forms of work organization capable of giving workers a more proactive role. It concludes that the reality of the organization of nursing work can be changed by nursing professionals' collective action in alliance with other organized sectors of society and in accordance with the health care users' needs.

Key words work in health care: work organization; organization of nursing work; nursing workers; unregistered nurses. 


\section{Introdução}

Este estudo aborda o trabalho em saúde e enfermagem com base na teoria sociológica e em algumas teorias do campo da administração. Da teoria sociológica, utilizamos, especialmente, as contribuições do materialismo-histórico-dialético sobre o processo de trabalho humano, uma abordagem crítica da sociologia das profissões e, também, a vasta bibliografia sobre as transformações que vêm ocorrendo no mundo do trabalho nas últimas décadas.

Analisamos três teses de doutorado (Capella, 1998; Pires, 1998; Gelbcke, 2002) e três dissertações de mestrado (Machado, 2002; Matos, 2002; Fertonani, 2003) publicadas entre 1998 e 2003, as quais abordam questões relativas à organização do trabalho da enfermagem. A seleção dos textos levou em conta os seguintes critérios: a) envolver pesquisa de campo com trabalhadores de enfermagem, seja em hospitais, seja em unidades assistenciais extra-hospitalares; b) ter sido realizada nos últimos oito anos; c) ter sido construída sob o referencial da pesquisa qualitativa e, dentro desta perspectiva, ter utilizado entrevistas para a coleta de dados, não descartando as pesquisas que empregaram também outros instrumentos para a coleta de dados, como grupo focal e estudo documental; d) incluir a opinião dos diversos componentes da equipe de enfermagem; e) ter utilizado o referencial sociológico para a análise do processo de trabalho em saúde e enfermagem. As referidas pesquisas analisaram o trabalho em saúde e enfermagem em sete diferentes instituições localizadas nas regiões Sul e Sudeste do Brasil quatro hospitais públicos, dois hospitais privados e unidades assistenciais de uma regional de saúde.

Com base nas formulações feitas pelos autores e nas idéias e opiniões apresentadas pelos profissionais de enfermagem, durante o processo das pesquisas, destacamos as categorias "processo de trabalho em saúde", "organização do trabalho em saúde" e "enfermagem" e indicações para uma nova forma de organização do trabalho da enfermagem. Na categoria organização do trabalho em saúde, ressaltamos as reflexões sobre gerenciamento e divisão do trabalho, relações de trabalho, condições de trabalho e relações com os usuários dos serviços de saúde. Em relação a cada categoria, foram realçadas tanto as idéias majoritárias formuladas pelos participantes das diversas pesquisas, bem como as que foram tratadas em apenas uma ou mais pesquisas, seguidas da devida indicação da fonte. Não houve divergência em relação às formulações apresentadas; no entanto, alguns aspectos foram tratados em apenas algumas pesquisas e foram, propositadamente, incluídos neste texto, porque contribuem para o entendimento da complexidade da temática.

Estruturamos o trabalho da seguinte forma. Em primeiro lugar, apresentamos reflexões teóricas sobre organização do trabalho. A seguir, focalizamos a organização do trabalho em saúde e enfermagem, destacando o fazer e o vi- 
ver dos trabalhadores de enfermagem de nível médio. Finalizamos o texto resgatando indicativos para uma nova forma de organização do trabalho da enfermagem, com base nas sugestões feitas pelos próprios trabalhadores de enfermagem em espaços de reflexão durante as mencionadas pesquisas.

\section{Organização do trabalho: considerações teórico-conceituais}

Organização do trabalho não se resume apenas à forma como o trabalho é desenvolvido, dividido ou mesmo ordenado. Dejours, Dessors e Desriaux (1993) afirmam que a organização do trabalho compreende a divisão do trabalho, o sistema hierárquico e as relações de poder, esclarecendo, assim, que ao dividir o trabalho, se impõe uma divisão entre os seres humanos. Dessa forma, a organização do trabalho pode ser entendida como um processo que envolve o conjunto de atividades desenvolvidas pelos trabalhadores incluindo as relações de trabalho e as relações hierárquicas. O trabalho ocorre em uma determinada estrutura organizacional, sendo influenciado pelo modo de gestão e pela cultura institucional, bem como pelas macropolíticas vigentes na sociedade. Nesse sentido, pensar a organização do trabalho não significa somente refletir sobre o modelo implementado internamente na referida instituição. Há que se pensar a totalidade que compõe este contexto e a sua inserção social sob um modo de produção localizado historicamente.

Entendemos organização do trabalho da enfermagem na perspectiva do materialismo histórico-dialético, o que envolve, portanto, dimensões macro e microssociais, bem como a dinâmica das relações que se estabelecem no trabalho. Organização do trabalho implica, assim: a) as relações entre os profissionais de enfermagem, as suas relações com os usuários dos serviços de saúde, com os outros profissionais de saúde ou grupos de trabalhadores da instituição; b) os constrangimentos e as facilidades provocados pela estrutura institucional; c) as relações hierárquicas; d) o conhecimento e as tecnologias disponíveis em saúde e na enfermagem; e) a divisão do trabalho; f) o modelo de gestão da instituição e da própria enfermagem; e g) as relações estabelecidas com as demais instituições que fazem parte do sistema de saúde (Pires, 2000a; Matos, 2002).

\section{Organização do trabalho e o fazer dos trabalhadores de enfermagem de nível médio}

O trabalho da enfermagem, segundo Capella (1998), Pires (2000a), Matos (2002) e Gelbcke (2002), é hoje, majoritariamente, um trabalho coletivo desenvolvido sob regras institucionais. É parte do trabalho coletivo em saúde 
no qual os trabalhadores de enfermagem estabelecem relações com a estrutura institucional, com outros profissionais e com os usuários desses serviços, buscando atender as necessidades dessa clientela.

\footnotetext{
“No trabalho coletivo em saúde os diversos profissionais de saúde desenvolvem parte do trabalho que tem como resultado, como produto, a assistência de saúde a indivíduos ou grupos. São atividades diferenciadas, que, estudadas nas suas especificidades, permitem identificar produtos distintos. Esses trabalhos, no conjunto, resultam na assistência a seres humanos que são totalidades complexas" (Pires, 2000b, p 255).
}

No espaço institucional, convivem características da divisão parcelar do trabalho, do trabalho coletivo do modo capitalista de produção, bem como características do trabalho profissional do tipo artesanal.

A manufatura estabelece uma nova forma de produção que expropria dos trabalhadores o domínio sobre o seu processo de trabalho e coloca a concepção do trabalho, a gerência do processo, as decisões sobre a organização e o preço do produto nas mãos dos proprietários dos meios de produção e dos gerentes, os quais assumem o controle da produtividade do trabalho. Esta forma de organizar o trabalho coletivo vem influenciando, até hoje, o gerenciamento e a divisão do trabalho nos diversos setores da economia. As formulações de Taylor sobre a "gerência científica", acrescidas da concepção fordista da linha de montagem, com a máquina controlando os tempos e movimentos do trabalho, ganharam espaço em todo o planeta, bem como têm sido objeto de muitas críticas (Braverman,1981; Edwards, 1979; Gorz, 1980; Fleury e Vargas, 1987). O setor industrial foi a mola propulsora do modo de produção capitalista; no entanto, essa lógica penetra em outros setores da economia como o setor de serviços, incluindo o setor saúde.

Entre os vários problemas mencionados como decorrentes da organização do trabalho taylorista/fordista, destacam-se: a fragmentação do trabalho com especialização dos trabalhadores para o exercício de tarefas delegadas; hierarquia rígida e controle gerencial do processo de produção; desequilíbrios nas cargas de trabalho; separação entre concepção e execução, levando à desmotivação e à alienação do trabalhador.

Nesse modelo, a gerência racionaliza a produção, definindo o modo e os tempos de produção, estabelecendo, rigidamente, os rendimentos dos trabalhadores e colocando-os sob uma estrutura hierárquica que vigia e fiscaliza a produção e que tem como principal objetivo o aumento da produtividade para obter o melhor rendimento do trabalho.

Trabalho profissional corresponde ao trabalho especializado, reconhecido socialmente como necessário para a realização de determinadas atividades. Origina-se das características do trabalho artesanal desenvolvido na 
Idade Média, nas corporações de artífices, no qual os produtores tinham controle sobre o seu processo de trabalho, controlavam o ritmo do trabalho, eram proprietários dos instrumentos de trabalho, tinham controle sobre o produto, bem como da produção e reprodução dos conhecimentos relativos ao seu trabalho (Braverman, 1981; Marglin, 1980; Marx, 1982).

Para discutir profissão, hoje, é preciso considerar as profundas modificações ocorridas no trabalho e nas profissões, em decorrência da estruturação do modo capitalista de produção, bem como as mudanças ocorridas no mundo do trabalho, nos últimos 30 anos. Considerando esse contexto, profissão designa um grupo de trabalhadores especializados na realização de determinadas atividades e que dominam os conhecimentos fundamentais à sua realização. Controlam a produção e reprodução dos conhecimentos necessários ao seu trabalho, por meio do ensino e da pesquisa, estabelecem regras para o exercício profissional e organizam-se em entidades do tipo associativo que os representam na sociedade (Pires, 1989, 1998).

Com base em todos os trabalhos analisados, é possível afirmar que, no cotidiano assistencial, o trabalho coletivo em saúde é exercido por múltiplos profissionais, no mínimo médicos e trabalhadores de enfermagem, além de outros profissionais e trabalhadores que desenvolvem uma série de atividades necessárias para o cuidado humano e para o funcionamento institucional, como, por exemplo, trabalhadores de escritório, manutenção, nutrição, etc.

O profissional médico tem sido o elemento central do processo assistencial em nível institucional. Os demais profissionais participam da assistência, subordinando-se às decisões médicas, mas cada categoria profissional mantém certa autonomia de avaliação e tomada de decisões. Os médicos, ao mesmo tempo em que dominam o processo de trabalho em saúde, delegam campos de atividades a outros profissionais de saúde como enfermagem, nutrição, fisioterapia, entre outros. Esses profissionais executam atividades delegadas, mas mantêm certo espaço de decisão e domínio de conhecimentos, típico do trabalho profissional (Pires, 1998). O trabalho em saúde envolve múltiplos profissionais, todavia, interdisciplinaridade em saúde é mais uma figura de retórica do que uma prática concreta.

O trabalho coletivo em saúde é, também, fortemente influenciado pelas características do trabalho coletivo do modo capitalista de produção com fragmentação, hierarquização e alienação. Essas características estão presentes na organização do trabalho em saúde, tanto no setor público quanto no setor privado. No setor público, contudo, a busca de maior rendimento do trabalho não é para a acumulação privada, e sim para a redução de custos do setor. O trabalho assalariado é predominante no setor público, mas, em ambos os setores, é possível encontrar outras formas de relação de trabalho, como a prestação de serviços autônomos ou através de cooperativas, bem como tem crescido a terceirização de diversas atividades. No que diz respeito 
ao trabalho médico, a relação de assalariamento aparece em menor escala no setor privado (Pires, 1998).

A enfermagem, na sua grande maioria, tem adotado princípios de organização baseados no taylorismo-fordismo, destacando-se a hierarquia rígida, a divisão do trabalho em tarefas, a ênfase no 'como fazer', a excessiva preocupação com manuais de procedimentos, rotinas, normas, escalas diárias de distribuição de tarefas e a fragmentação da assistência.

Esta verticalização é referendada também pela Lei do Exercício Profissional no 7.498, de 25 de junho de 1986, e pelo Decreto no 94.406, de 8 de junho de 1987, os quais definem as atribuições dos componentes da equipe de enfermagem e prescrevem que os enfermeiros e enfermeiras são os responsáveis pela supervisão do trabalho dos demais componentes da equipe.

Com base nos resultados de duas pesquisas realizadas em três diferentes hospitais da região Sul do país, Matos (2002) e Gelbcke (2002) ressaltaram aspectos das escolas administrativas que influenciam o modo de organização do trabalho da enfermagem, entre os quais destacamos:

- da escola clássica — as estruturas altamente hierarquizadas sob o ângulo vertical e a departamentalização sob o ângulo horizontal (ou seja, unidades específicas, para cuidados específicos, clínica médica, cirúrgica, pediátrica, masculina, feminina, e assim por diante). A especialização do conhecimento em saúde reflete, também, a concepção cartesiana e positivista de ciência que tem forte influência no modo de produzir conhecimentos em saúde, bem como na formação dos profissionais de saúde e na organização institucional. A escola clássica influenciou, também, a ênfase institucional na subordinação de um indivíduo a outro e de um serviço a outro, além dos organogramas verticalizados, que não consideram as relações interpessoais. Deste modelo adotam-se as propostas de trabalho e avaliação basicamente quantitativas; a preocupação com a quantidade de trabalho realizado e não com a qualidade deste; o controle do trabalhador, por meio do papel do supervisor (enfermeiros chefes de unidade e/ou responsáveis pelo trabalho da equipe em determinado turno de trabalho). O modelo adotado na saúde, tendo por base a escola clássica, privilegia a distribuição de atribuições e tarefas que disciplinam o trabalhador ao extremo; a disciplina rígida imposta por normas e rotinas que estabelecem a ordem, o lugar e o tempo certo em que pessoas e materiais devem estar;

- da escola burocrática de Weber - a divisão do trabalho e hierarquia de autoridade, com cargos organizados de forma piramidal ou escalar (organogramas que definem o controle de um nível hierárquico sob outro); a regulamentação por meio de normas, procedimentos e rotinas rígidas, formais e escritas, visando à uniformidade e que impedem a manifestação da subjetividade, levando à impessoalidade, principalmente nas relações; a ênfase na competência profissional e técnica, com admissão por concursos e provas de 
seleção (ainda hoje utilizadas com freqüência, muitas vezes provas apenas descritivas, sem entrevistas ou outra forma de seleção que permita a expressão do trabalhador);

- da escola das relações humanas - aspectos relacionados à liderança, motivação, comunicação e dinâmica de grupos (utilizadas tanto junto à equipe, quanto com os usuários, em momentos relacionados à educação para a saúde), bem como indicativos de possibilidades de uma participação maior dos trabalhadores nos processos decisórios (principalmente relacionados aos enfermeiros, já que ainda não se tem na enfermagem uma participação mais efetiva dos trabalhadores de nível médio nos processos decisórios);

- da teoria dos sistemas, difundida na área da saúde por Mário Chaves a idéia de uma rede institucional para prestar assistência de saúde, concebida como um sistema hierarquizado e constituído de vários subsistemas (centros de saúde, hospitais e outros). A enfermagem incorpora parte desta concepção, principalmente no que se refere ao estabelecimento de metas, objetivos e finalidades, adequando-se ao estabelecido pela instituição, em detrimento, algumas vezes, das necessidades e especificidades da realidade local;

- da teoria contingencial - a enfermagem tem-se utilizado pouco desta teoria, que é "eminentemente eclética e integrativa, pois tende a assimilar os conceitos das diversas teorias da administração" (Chiavenato, 1999, p. 837). A teoria contingencial considera as contribuições de outras teorias no uso das cinco variáveis básicas da teoria administrativa: tarefas, pessoas, tecnologia, ambiente e estrutura. No cotidiano de gestão, ela relativiza as questões, considerando o ambiente e sua relação com as demais estruturas sociais e econômicas. Para a enfermagem, a instituição é que sobressai, não a interface da mesma com os usuários e com os trabalhadores, considerando-se a sua saúde, subjetividade, criatividade e satisfação com o trabalho;

- do modelo japonês, toyotista, de qualidade total - encontra-se a 'exigência' de qualidade da assistência, sem, contudo, permitir uma maior autonomia e flexibilidade no processo de trabalho. A rotatividade entre os diferentes locais/setores é aplicada quando atende uma exigência institucional. Em alguns casos, rodam os trabalhadores sem critérios definidos ou a rotatividade pode ocorrer por solicitação dos trabalhadores, mas ela só é possível quando existem 'vagas' disponíveis nos setores solicitados. Adota-se, também, a responsabilização do trabalhador, o qual deve 'vestir a camisa' da instituição, no sentido de comprometer-se integralmente com a mesma;

- da gestão participativa - algumas instituições têm buscado a flexibilização das relações de trabalho, permitindo uma participação maior dos trabalhadores, por meio de representações em comissões e em planejamentos ou de consultas para tomadas de decisões. Em relação à enfermagem, existem alguns casos localizados, nos quais geralmente ocorrem experiências 
democráticas de gestão. Neles, destacam-se a valorização e a participação do conjunto dos trabalhadores de enfermagem e de usuários dos serviços.

Considerando-se o trabalho da enfermagem como um todo, é possível dizer que sua organização inclui aspectos das diferentes abordagens administrativas, principalmente do modelo clássico, da escola das relações humanas, da teoria dos sistemas, além da incorporação de alguns princípios da qualidade total.

Majoritariamente, o fazer da enfermagem, principalmente dos trabalhadores de nível médio, permanece carregado de normas, rotinas, da realização de tarefas fragmentadas, sem participação efetiva do conjunto da equipe nos processos decisórios. Poucas são as iniciativas que buscam a subjetividade do trabalhador e o consideram um sujeito ativo e reativo no processo de trabalho. O fazer continua sendo o principal motor no trabalho de nível médio. Mesmo novas formas de divisão do trabalho coletivo da enfermagem, como o modelo de 'cuidados integrais', pelo qual o trabalhador presta todos os cuidados de enfermagem necessários a um usuário (ou grupo de usuários), não têm possibilitado a real participação dos trabalhadores na tomada de decisão, já que os cuidados são prescritos pelos médicos e enfermeiros, sem uma discussão mais ampliada com aqueles que cuidam (Matos e Pires, 2002).

Além disso, em muitas instituições, a divisão do trabalho na equipe de enfermagem se dá segundo o modelo de divisão por tarefas, pelo qual cada trabalhador executa cuidados parcelares, ou seja, executa as mesmas tarefas específicas estabelecidas para aquele dia de trabalho para o conjunto dos usuários que têm essas atividades prescritas. Essa modalidade de prestação de 'cuidado por tarefa' fragmenta o trabalho e aproxima-se do modelo taylorista-fordista de organização do trabalho, dificultando a interação sujeitosujeito.

Tendo em vista que é sobre o fazer que os trabalhadores são 'cobrados' e mesmo 'lembrados', ao serem questionados acerca do que é organização do trabalho, relacionam-na, sobretudo, com divisão de tarefas, tempo, ritmo do trabalho, ou seja, apenas com os aspectos associados à realização da tarefa em si, não mencionando a autonomia e a participação nas decisões como fatores ligados à organização do trabalho. Essa forma de organização do trabalho, que preconiza a ordem, a disciplina, o controle, impede uma participação mais ativa e criativa dos trabalhadores nos processos decisórios, mesmo quando isto diz respeito ao desenvolvimento de procedimentos técnicos (Gelbcke, 2002).

Essa preocupação constante com o fazer, com a realização da tarefa em si está relacionada à forma como a enfermagem tem valorizado o seu trabalho, o fazer em detrimento do pensar. Essa relação com a eficiência, com o fazer, está também associada ao que se espera do trabalhador na sociedade 
atual: eficiência, agilidade, produtividade, aspectos presentes no cotidiano de trabalho da enfermagem. Busca-se o trabalhador mais ágil, que se comprometa em realizar bem o trabalho técnico, que realize as técnicas de enfermagem com precisão, mesmo que de forma robotizada, esquecendo, algumas vezes, que se está aplicando uma técnica num outro ser humano, que sente dor, medo e que, por vezes, precisa mais de alguém que lhe dê um sorriso, um aperto de mão, que lhe faça um carinho, do que simplesmente execute uma técnica. Nessa relação, o prazer do processo criativo envolvido no trabalho humano é pouco considerado, ou pelo menos difícil de expressar-se.

Porém, há que se salientar que, para que o trabalho seja realizado a contento, também são necessárias boas condições. Os estudos de Matos (2002) e Gelbcke (2002) assinalam, como importantes para a organização do trabalho, aspectos relacionados à quantidade e qualidade da força de trabalho disponível; às condições contratuais, incluindo o respeito aos direitos trabalhistas, bem como às condições do ambiente de trabalho e à quantidade e qualidade dos instrumentos de trabalho.

A organização do trabalho não está apenas relacionada à atividade em si, mas também às relações de trabalho, que nascem de relações sociais de produção, as quais constituem a interação entre os diferentes agentes sociais. Tais agentes, muitas vezes, ocupam posições complementares e similares, visíveis, por exemplo, nas relações que ocorrem entre trabalhadores que estão em posições opostas e complementares no processo produtivo, tais como, trabalhadores e empregadores. Essas relações que se estabelecem no interior das organizações e que fazem parte da organização do trabalho sofrem influência de variáveis internas do próprio ambiente organizacional, bem como de variáveis externas, da própria sociedade.

A organização do trabalho tem, portanto, um papel de destaque na vida do trabalhador, tanto pelo modo como o próprio trabalho é realizado, quanto pelas inter-relações estabelecidas, ou seja, a organização do trabalho aparece como uma relação intersubjetiva e uma relação social. Dessa forma, não se pode pensar na organização do trabalho só de forma técnica, da forma como o trabalho é operado. Ela é técnica, mas passa, também, por uma integração humana, que a modifica e lhe dá forma concreta.

\section{Reflexos da organização do trabalho no viver dos trabalhadores de enfermagem de nível médio}

Na enfermagem, a forma como o trabalho se encontra organizado não dá espaço para que o sujeito trabalhador reflita sobre seu trabalho, suas alegrias, 
suas tristezas, seu prazer, seu sofrimento. Não permite que ele se sinta como um sujeito humano.

Diz Leopardi (1999, p. 173) que a "pausa do trabalho é importante para a liberdade, porque é quando refletimos, concebemos a continuidade, sentimos reverência, sentimos o mundo". Parece não haver espaço para a pausa no mundo do trabalho, porque, se houver, a alienação será menos flagrante e os trabalhadores pensarão mais em seus direitos como cidadãos.

Além disso, pela característica de cuidar de seres humano que inclui situações de sofrimento, os trabalhadores de saúde, entre os quais os de enfermagem, enfrentam sentimentos e ansiedades profundos e intensos na sua rotina de trabalho, o que se reflete em desgaste, pois não é nada agradável deparar-se com a dor e a morte alheias. Essa especificidade do trabalho em saúde torna ainda mais evidente como a organização tem interferido no processo de desgaste dos trabalhadores, quer pela impossibilidade do trabalhador manifestar sua subjetividade, quer por ter que se comprometer com a instituição que lhe consome e faz com que o trabalho se torne a sua principal referência. Apesar de cada instituição ter sua singularidade, de uma forma geral, como já foi examinado anteriormente, nas instituições de saúde há traços significativos do modelo taylorista, funcionalista e burocrático de gestão que dificultam a manifestação da subjetividade e criatividade dos trabalhadores. De acordo com Cecílio, existem certas regularidades presentes nas organizações de saúde, destacando-se:

“o forte poder médico traduzido em sua autonomia e na sua acentuada capacidade de impor disciplinas no hospital; a linha de mando fortemente hierarquizada da enfermagem, mas também estratégias de resistência dos subalternos, verdadeiras 'linhas de fuga' ao poder instituído” (Cecílio, 1999, p. 318).

Nas instituições em que há um predomínio de autoridade racional e legal, uma rígida hierarquia vertical, com uma sistemática divisão do trabalho, além de normas, rotinas e regulamentos que conduzem o trabalhador de enfermagem a um processo de rotinização e de alienação, existe uma dificuldade de manifestações e de mobilizações que visem a uma mudança. Existe, desta forma, uma passividade coletiva, que, para alguns estudiosos, é conseqüência da falta de perspectivas alternativas, tanto econômicas quanto sociais e políticas. Dejours (1999) afirma que as possibilidades de uma mobilização estariam ligadas mais a uma reação contra o intolerável, do que propriamente a uma ação voltada à busca de felicidade.

No entanto, quando existem algumas iniciativas de gestão que permitem e até mesmo estimulam a participação dos trabalhadores, geralmente ocorre um certo grau de empenho por parte dos mesmos. Outro movimento de reação à alienação e ao amordaçamento causado pela organização autori- 
tária e fragmentada do trabalho é a adesão dos trabalhadores de saúde e enfermagem aos movimentos de greve.

Essa participação em movimentos grevistas ocorre, principalmente, nas instituições públicas. Nas instituições privadas é mais difícil, pela forma de inserção dos trabalhadores no mercado de trabalho, já que o setor privado tem como instrumento legal de controle dos trabalhadores a CLT, que facilita aos patrões o processo de demissão. Em um mercado de trabalho restrito e com precarização crescente, fica mais fácil para os patrões utilizarem a rotatividade da mão-de-obra e mais difícil para os trabalhadores aderirem a movimentos grevistas. Nas instituições públicas, apesar de todo o controle do Estado e das restrições de investimento da política neoliberal, os trabalhadores contam com a estabilidade no emprego, o que possibilita 'alguma' forma de reação mais coletiva.

O medo e a falta de perspectiva influenciam negativamente o ser e o viver dos trabalhadores. Há, portanto, que se pensar em novas formas de organização do trabalho, que lhes permitam serem atores da história, sujeitos críticos, criativos e proativos.

\section{Novas possibilidades: repensando o trabalho da enfermagem}

Repensar o trabalho da enfermagem, visando a torná-lo algo mais inteiro, prazeroso, completo, que permita ao trabalhador sentir-se sujeito da história, torna-se um desafio, mas também um exercício, já que mudanças concretas da prática implicam o envolvimento daqueles que vivem o cotidiano das instituições, quer na posição de trabalhador de enfermagem ou de usuário do serviço, além da própria da capacidade de intervenção desses sujeitos. Para tanto, processos participativos se fazem necessários, para que se possa restituir "aos sujeitos o sentimento de esperança nas possibilidades de futuro" (Matos, 2002, p. 125). Dessa forma, apresentamos algumas sugestões que possibilitem o repensar da organização do trabalho, pois as mudanças só ocorrerão a partir do momento em que os envolvidos participarem, refletirem e decidirem sobre o que transformar, o que querem, o que necessitam, o que podem alterar.

Merhy afirma que

“estamos vivendo uma situação histórico-social, que tem definido para as organizações produtivas um desafio que só pode ser enfrentado através de modelos gerenciais cada vez menos burocráticos, e que permitem às organizações uma plasticidade que as transformam quase em um 'organização inteligente', que consiga assimilar o que ocorre no seu interior e na sua volta, e elaborar soluções adequadas para cada problema novo que aparece. A gestão seria o campo tecnológico para dar às organizações esta plasticidade" (Merhy, 1997, p. 93). 
Nesse sentido, pautados pelos indicativos formulados pelos trabalhadores de enfermagem participantes dos estudos mencionados, destacamos alguns aspectos que devem ser considerados para se repensar um novo modo de organização do trabalho, principalmente quando pensamos na enfermagem como uma equipe e nos trabalhadores de nível médio e usuários dos serviços de saúde como sujeitos participantes deste processo.

- $\quad$ experiências que diminuam a distância entre concepção e execução do trabalho, envolvendo trabalhadores e usuários no planejamento global da assistência;

- reconhecimento do papel dos trabalhadores na vida da instituição, com a adoção de mecanismos participativos de gestão, com a responsabilidade dos trabalhadores com os objetivos e práticas institucionais, substituindose as formas autoritárias de controle por espaços que permitam a manifestação da criatividade e iniciativa do trabalhador;

- o papel dos gestores seria de intermediadores nos processos de negociação, quer internos à unidade em que trabalham, na instituição, quer envolvendo outras corporações;

- definição de normas e padrões flexíveis que favoreçam o desenvolvimento de mecanismos facilitadores da criatividade e da responsabilidade social;

- definição de estruturas de educação continuada no trabalho que considere o trabalhador de enfermagem em suas dimensões pessoal, profissional e institucional, preocupando-se com o crescimento global do ser humano; - condições de trabalho compatíveis com o trabalho a ser realizado, possibilitando uma assistência de qualidade, bem como visando à saúde do trabalhador. Essas condições estão relacionadas à existência de infra-estrutura adequada, bem como de recursos materiais e humanos, em quantidade e qualidade para o trabalho a ser desenvolvido;

- utilização de tecnologia adequada ao trabalho, considerando as necessidades dos trabalhadores e a sua utilidade técnico-social;

- $\quad$ estabelecimento de relações de trabalho pautadas no diálogo, no trabalho em equipe, em comunicação autêntica, na ética, na solidariedade e no compromisso profissional, tanto no que se refere aos profissionais, quanto destes com os usuários;

- fortalecimento do trabalho numa perspectiva interdisciplinar, de integração das ações e de assistência integral, com a participação efetiva de todos os trabalhadores, independentemente de seu grau de formação;

- fortalecimento da dimensão ética do trabalho em saúde e especificamente da enfermagem, na construção de relações solidárias entre os trabalhadores de saúde, entre os trabalhadores de enfermagem e desses com o usuário; - valorização dos profissionais, por meio de ações que visem à humanização das relações interpessoais, já que o trabalhador de enfermagem também tem necessidade de ser cuidado, de ser valorizado; 
- valorização dos processos intersubjetivos, visando à criatividade, à autonomia, à afetividade;

- implementação de modelos de gestão mais democráticos, que permitam aos trabalhadores serem sujeitos participativos do processo de trabalho e não meros executores de ações delegadas. Para tanto, é imprescindível a adoção de modelos que prevejam direção colegiada, com organogramas horizontalizados e liderança compartilhada, o que permite, de certa maneira, diluir o poder.

\section{Considerações finais}

As pesquisas que fundamentaram nossas reflexões delineiam um quadro complexo no que diz respeito à organização do trabalho da enfermagem no país, com predominância da fragmentação do trabalho e do parcelamento de tarefas sob o controle gerencial de enfermeiros e enfermeiras. Esse modelo majoritário tem múltiplas determinações.

De um lado, é produto da influência dos modelos gerencias e administrativos dominantes na sociedade, os quais exercem influência na organização do trabalho nas instituições de saúde, bem como na organização do trabalho interna à profissão. De outro, a organização do trabalho da enfermagem é produto da concepção política majoritária na categoria, uma vez que a legislação vigente sobre o exercício profissional da enfermagem teve participação ativa de representantes da categoria. Apesar do embate de posições divergentes, algumas posições mais avançadas que buscavam tanto romper com a fragmentação quanto aproximar-se mais com as características de um trabalho profissional foram derrotadas pela visão segundo a qual a valorização profissional e o reconhecimento social da profissão viriam com a delimitação de papéis, destacando para enfermeiros e enfermeiras o papel de gerenciamento e coordenação do trabalho coletivo.

A visão vencedora defendia que a disposição, em lei, de ações privativas para enfermeiros e enfermeiras garantiria um papel de destaque para esses profissionais, bem como contribuiria para ampliar a contratação de trabalhadores de enfermagem com grau universitário pelos estabelecimentos assistenciais.

No nosso entendimento, trata-se de uma visão equivocada. A história tem mostrando que a presença de múltiplos exercentes, com formações diferenciadas e competências estabelecidas legalmente, se identifica com os interesses gerencias e dos proprietários dos estabelecimentos de saúde, visando ao barateamento do trabalho. Ou seja, corresponde ao que já foi tão bem explicado por Marx (1982) e Braverman (1981): fragmentação do trabalho, especialização de trabalhadores para tarefas específicas, hierarquização 
de funções e de valor da hora trabalhada, com vistas a aumentar a produtividade com menor custo.

É importante definir a capacitação teórico-instrumental necessária para o exercício do trabalho profissional de enfermagem. Uma profissão com múltiplos exercentes, com graus de formação diferenciada, pode ser mais barata, mas é injusta com os trabalhadores que recebem demandas complexas, mas são remunerados considerando o grau de formação que receberam. Além disso, os trabalhadores de enfermagem de nível médio têm sido, sistematicamente, alienados do processo de planejamento e de avaliação do trabalho de enfermagem.

Ainda, o trabalho de enfermagem desempenhado por um grupo de profissionais com o mesmo nível de formação não é por si só uma garantia de melhora na qualidade da assistência, nem de melhoria automática nas relações de trabalho. É preciso pautar a prática profissional por concepções de gestão participativa, de trabalho criativo e emancipatório, de prática baseada em princípios éticos, de identidade com as necessidades do conjunto da sociedade e das pessoas que precisam de cuidados profissionais de enfermagem para realmente produzir um melhoria na qualidade da assistência prestada, bem como obter o reconhecimento por parte da sociedade do valor social do cuidado humano.

\section{Notas}

1 Professora adjunta da Universidade Federal de Santa Catarina. Doutora em Ciências Sociais pela Universidade Estadual de Campinas com Pós-Doutorado na Universidade de Amsterdã, Holanda. <piresdp@yahoo.com.br>.

2 Professora adjunta da Universidade Federal de Santa Catarina. Doutora em Enfermagem pelo Programa de Pós-Graduação em Enfermagem da UFSC. <fgelbcke@nfr.ufsc.br>.

3 Enfermeira do Hospital Universitário Polydoro Ernani de São Thiago - Universidade Federal de Santa Catarina. Mestre em Enfermagem pelo Programa de Pós-Graduação em Enfermagem da UFSC.<elianematos@hotmail.com>. 


\section{Referências}

BRAVERMAN, Harry.1981.Trabalho e capital monopolista. 3.ed. Rio de Janeiro: Zahar.

CAPELLA, Beatriz Beduschi. 1998. Uma abordagem sócio-humanista para um "modo de fazer" o trabalho da Enfermagem. Pelotas/ Florianópolis: UFPEL/UFSC.

CECÍLIO, Luiz Carlos. 1999. Autonomia versus controle dos trabalhadores: a gestão do poder no hospital. Ciência \& Saúde Coletiva, v. 4, n. 2, p. 315-329.

CHIAVENATO, Idalberto. 1999. Introdução à teoria geral da administração. 5.ed. Rio de Janeiro: Campus.

DEJOURS, Christophe. 1999. A banalização da injustiça social. 2. ed. Rio de Janeiro: Editora FGV.

; DESSORS, Dominique; DESRIAUX, François. 1993. Por um trabalho, fator de equilíbrio. Trad. Maria Irene S. Betiol. Revista de Administração de Empresas, v. 33, n. 3, p. 98-104.

EDWARDS, R. 1979. Contested terrain: the transformation of workplace in the twentieth century. New York: Basic Books.

FERTONANI, Hosanna Patrig. 2003. O desafio de construir um novo modelo assistencial em saúde: reflexões de trabalhadores do PSF de uma unidade de saúde de Maringá PR. Dissertação de Mestrado, Florianópolis: Programa de Pós-Graduação em Enfermagem, Universidade Federal de Santa Catarina.

FLEURY, Afonso C. C.; VARGAS, Nilton (orgs). 1987. Organização do trabalho. São Paulo: Atlas.

GELBCKE, Francine Lima. 2002. Interfaces dos aspectos estruturais, organizacionais e relacionais do trabalho de enfermagem e o desgaste do trabalhador. Tese de Doutorado, Florianópolis: Programa de PósGraduação em Enfermagem, Universidade Federal de Santa Catarina.

GORZ, André. 1980. Crítica da divisão do trabalho. São Paulo: Martins Fontes.

LEOPARDI, Maria Tereza (org). 1999. O processo de trabalho em saúde: organização e subjetividade. Florianópolis: Papa-Livros.

MACHADO, Rosani Ramos. 2002. A passagem de plantão no contexto do processo de trabalho da enfermagem. Dissertação de Mestrado, Florianópolis: Programa de Pós-Graduação em Enfermagem, Universidade Federal de Santa Catarina.

MARGLIN, Stephen. 1980. Origem e funções do parcelamento das tarefas. In: GORZ, A. (org.) Crítica da divisão do trabalho. São Paulo: Martins Fontes, p. 37-77.

MARX, Karl. 1982. O capital. 8. ed. São Paulo: Difel. Livro 1. v.1.

MATOS, Eliane. 2002. Novas formas de organização do trabalho e aplicação na enfermagem: limites e possibilidades. Dissertação de Mestrado, Florianópolis: Programa de Pós-Graduação em Enfermagem, Universidade Federal de Santa Catarina.

; PIRES, Denise. 2002. A organização do trabalho da enfermagem na perspectiva dos trabalhadores de um hospital escola. Texto \& Contexto Enfermagem, v. 11, n. 1, p.187-205.

MERHY, Emerson Elias. 1997. Em busca do tempo perdido: a micropolítica do trabalho vivo em saúde. In: MERHY, E.; ONOCKO, R. (orgs.) Praxis en salud: un desafio para lo público. Buenos Aires/ São Paulo: Lugar Editorial/Hucitec, p.71112.

MORIN, Estelle M. 2001.Os sentidos do trabalho. RAE - Revista de Administração de Empresas, v. 41, n. 3, p.8-19.

PIRES, Denise. 1989. Hegemonia médica na saúde e a enfermagem. São Paulo: Cortez. 1998. Reestruturação produtiva e trabalho em saúde no Brasil. São Paulo: Annablume.

2000a. Novas formas de organização do trabalho em saúde e na enfermagem. Revista Baiana de Enfermagem, v. 13, n. 1-2, p. 83-92.

2000b. Reestruturação produtiva e conseqüências para o trabalho em saúde. Revista Brasileira de Enfermagem, v. 53, n. 2, p. 251-263.

Recebido em 13/04/2004

Aprovado em 14/07/2004 